\title{
Alvarado score in the diagnosis of acute appendicitis: correlation with the tomographic and intra- operative findings
}

\begin{abstract}
Background: Acute appendicitis is one of the most common causes of abdominal pain, accounting for about one-third of patients presenting at emergency services with acute abdomen. A high degree of suspicion is essential for diagnosis.
\end{abstract}

Aim: Evaluate the correlation between the Alvarado score and the tomographic and Intraoperative findings of patients with acute appendicitis.

\begin{abstract}
Methods: Descriptive, cross-sectional, retrospective study using data obtained from the Internment Management System of all hospitalized patients with acute appendicitis from June 2014 to June 2015. Data were analyzed and Statistics generated through the Epi Info 7.0 program.
\end{abstract}

Results: 240 patients were evaluated. Of these, $150(62.5 \%)$ were male and $90(37.5 \%)$ were female, with a mean age of 28.6years. The exclusive clinical diagnosis was performed in 42 patients( $17.4 \%$ ). The relationship between the positive Alvarado score and the tomographic findings was evaluated, being considered positive in the presence of two or more findings. The positive association between Positive Alvarado Score and the presence of tomographic findings was obtained, with Odds Ratio of 1.665 and $\mathrm{P}=0.1805$. The association between the intraoperative findings and the positive Alvarado score was evaluated, in which $8(11.11 \%)$ patients were in the edematous phase(Odds Ratio $=0,8182 \quad \mathrm{P}=0,6474), \quad 31(43,05 \%)$ were phlegmonous(Odds Ratio $=0,8128, \mathrm{P}=0,4655), 15(20.83 \%)$ in the gangrenous phase (Odds Ratio $=0,9175$, $\mathrm{P}=0,8028)$ and $18(25 \%)$ in the perforated phase(Odds Ratio $=1,7949, \mathrm{P}=0,1278)$.

Conclusion: There is a positive association between Alvarado score and the presence of tomographic findings, as well as the association between positive Alvarado score and perforation phase.

Keywords: appendicitis, appendectomy, acute abdomen, tomography, diagnosis

\author{
Volume 5 Issue I - 2018 \\ Christian Spina, Ana Paula Marconi lamarino, \\ Otto Mauro dos Santos Rosa, Marcelo \\ Augusto Fontenelle Ribeiro \\ Universidade Santo Amaro, Brazil
}

\begin{abstract}
Correspondence: Marcelo Augusto Fontenelle Ribeiro, Livre Docente da Disciplina de Cirurgia Geral, Chefe do Núcleo de Clínica Cirúrgica da Universidade Santo Amaro, Coordenador do Programa de Residência Médica em Cirurgia Geral, Laparoscópica e Trauma da Unisa, SP, Brasil, Email fribeiro@unisa.br
\end{abstract}

Received: February 04, 2018 | Published: February 21, 2018

\section{Introduction}

Acute appendicitis(AA) is one of the most common causes of abdominal pain, accounting for about one-third of patients presenting to emergency services with acute abdomen. Surgeons perform about 280,000 appendectomies per year in the United States. ${ }^{1-3}$ Despite the high prevalence, its diagnosis remains a challenge mainly among young, elderly and women of child-bearing age, where a number of other inflammatory, genitourinary and gynecological conditions may present signs and symptoms that are similar to this condition. ${ }^{2}$ A delay in performing the appendectomy increases the risk of perforation of the appendix, which increases the morbidity and mortality. ${ }^{3}$ A high degree of suspicion is essential for the diagnosis of this patology. The diagnosis of in patients with typical clinical findings can be made based on clinical and laboratory tests. Pains in the lower right quadrant, migration of pain, anorexia, nausea or vomiting, fever, leukocytosis are effective and practical criteria for such diagnosis. However, about one-third of the patients will present with atypical clinical and laboratory findings, requiring radiological complementation. ${ }^{1,4}$ Thus, a numerical scale was created by Alvarado based on clinical data and blood count to identify the probability of being a case of AA. ${ }^{5}$ Alvarado's original work was published in 1988 and is based on his retrospective analysis of data from 305
Patients with abdominal pain suggesting AA. Eight predictive factors of diagnostic value in AA were identified and a score of 1 or 2 was assigned to each factor based on its predictive value for diagnosis. ${ }^{5,6}$ The score of 1 was given for each of the criteries following: elevation of temperature greater than $37.3^{\circ} \mathrm{C}$, pain in the lower right quadrant, migratory pain to the lower right quadrant, anorexia, nausea or vomiting, and increased granulocytic series. The Alvarado score(AS) of 2 was given for two criteries: discomfort in the lower right quadrant and leukocytosis $(>10,000))^{5,6}$ Conduct recommendations are given based on the total score. An AS between 5-6 is "compatible" with the diagnosis of AA and is recommended routine examination or clinical observation, with a diagnostic probability of $66 \%$. Facing a score of 7-8, the diagnosis of appendicitis is "likely," and a score of 9 or 10 is "very likely" to be in the presence of an AA, both requiring surgical intervention. The probability to be between $7-10$ is $93 \%$. A value up to 4 tends to exclude this condition, with a probability of $30 \% .6,7$ According to the score of this scale, imaging methods can be added to the investigation, being the abdomen ultrasound and the computed tomography $(\mathrm{CT})$ of the abdomen and pelvis, the main ones. If the AS is $\geq 7$, surgery without complementation may be indicated by imaging studies. The choice between US and CT of the abdomen varies and depends on certain factors, such as the preference and experience of the institution, age, sex, biotype of 
the patient and duration of the clinical history. ${ }^{8}$ The ultrasound of abdomen is indicated as initial method, mainly for children, young women and pregnant women, since it does not emit ionizing radiation and also assists in the differential diagnosis of other causes of acute abdomen. However, with no visualization of the appendix, one should continue the study with $\mathrm{CT}$, which represents the most used imaging study for patients with suspected AA. ${ }^{5,9}$ Technological advances and increasing availability have fundamentally changed the approach to suspected AA. Several authors suggest routine CT for patients with $\mathrm{AS} \leq 4.7{ }^{7,9}$ Complementation by such methods is important for atypical symptoms, retrocecal localization appendix, obese patients, and disease-related complications

Considering its cost, radiation risk and potential delay of therapeutic intervention, CT should be reserved for the cases cited above. With a sensitivity of $87 \%$ to $100 \%$ and a specificity of $95 \%$ to $100 \%$, CT with contrast is the most reliable diagnostic test for AA. Such an examination is extremely important in differential diagnosis and to reduce the rate of negative appendectomies. ${ }^{5}$ The objective of the present study is to evaluate the correlation between the Alvarado score and the tomographic and intraoperative findings of patients with acute appendicitis.

\section{Methods}

The study was carried out at Grajaú General Hospital, using the database of the period from June 2014 to June 2015. This is a descriptive, intersectional, retrospective study using data obtained from the Management System such as hospitalar admission, pre and postoperative exams, surgical data and the evolution of all cases of acute appendicitis. Inclusion criteria include all patients diagnosed with acute appendicitis in this period, excluding the pediatric population(less than 13years old) from the study. The research is made up of patients of both sexes. It was not possible to calculate the Alvarado score for 2 patients and in 8 patients the anatomopathological examinations were not obtained due to laboratory results unavailability. The use of the free informed consent term for the present study does not apply, since it is based only on the medical records of patients with acute appendicitis, and the data obtained will be kept confidential, without any type of intervention. Statistical analysis was performed using the Epi-Info 7 software. The categorical variables in each group were compared by Chi-square test and Fisher's exact test(if more than $20 \%$ of the expected frequencies were less than 5). Continuous variables were compared using independent Student's t-test and $p=<0.05$ was considered statistically significant. Approval in the Ethics Committee in Research $\mathrm{n}^{\circ} 1269716$.

\section{Results}

A total of 379 appendectomies were performed, and 139 pediatric patients were excluded from the sample. A total of 240 patients were studied. Of these, $150(62.5 \%)$ were male and 90(37.5\%) were female, with a mean age of 28.6years. The exclusive clinical diagnosis of AA, without complementation by imaging tests, was performed in 42 patients(17.4\%). Abdominal US and CT showed sensitivity of $39.13 \%$ and $96.52 \%$, respectively. The US and TC specificities were $40 \%$ and $25 \%$, respectively. The positive predictive value(PPV) was $92.30 \%$ for the US and $95.86 \%$ for the CT. The US accuracy of $39.17 \%$ and $92.76 \%$ for CT(Table 1$)$.

Out of a total of $97(40.41 \%)$ patients who had abdominal US, $39(40.2 \%)$ had a diagnosis of AA. Of these, 7(17.95\%), despite the diagnosis already established, continued with the tomographic study.
Abdominal CT was requested for 152 patients(63.33\%). Of this number, 145(95.39\%) were diagnosed with AA. In 11 patients(4,76\%), pathological examination revealed appendicitis in the edematous phase, 157 in the phlegmonous phase(67.97\%), 45(19.48\%) in the gangrenous phase and 2 in the necrotic phase $(0.87 \%)$. The number of negative appendectomies was 16 patients(6.93\%). Taking into account the classification made by Alvarado, the following data were obtained: AS $0-4 ; 46(19.33 \%)$, AS 5-6; 120(50.42\%) and AS 7-10; $72(30.25 \%)$, out of a total of 238 patients of that it was possible to perform the calculation(Table 2).

Table I Sensitivity and specificity between diagnostic methods

\begin{tabular}{llll}
\hline & AS (\%) & US (\%) & TC (\%) \\
\hline Sensitivity & 30,63 & 39,13 & 96,52 \\
Specificity & 75 & 40 & 25 \\
Accuracy & 33,61 & 39,17 & 92,76 \\
VPP & 94,44 & 92,30 & 95,86 \\
\hline
\end{tabular}

AS, alvarado score; US, ultrasound; CT, computed tomography

Table 2 Results obtained with the application of AS in the sample

\begin{tabular}{llll}
\cline { 2 - 3 } AS & Patients & (\%) \\
\hline $0-4$ & 46 & $19,33 \%$ \\
6-May & 120 & $50,42 \%$ \\
I0-Jul & 72 & $30,25 \%$ \\
AS, alvarado score & TOTAL & 238 & $100,00 \%$ \\
\cline { 2 - 3 } & & &
\end{tabular}

After the AS was obtained, the patients were divided according to the following results: $21(8.82 \%)$ patients with a score of $0-3$, $185(77.73 \%)$ were between $4-7$, and $32(13,44 \%)$ between $8-10$. Of the patients with Alvarado score between 0-3, 13(61.9\%) patients were diagnosed with appendicitis by abdominal CT, with a score of 4-7 were $112(60.54 \%)$ and between 8-10 were 19(59.37\%) diagnosed with this condition by CT. For AS with cutoff point of 8 for the diagnosis of AA, the sensitivity of the AS was $13.45 \%$, with the PPV being $96.87 \%$. When the numbers mentioned by Alvarado were used, 30(65.21\%) of the patients with AS 0-4 were submitted to CT, and in 28 cases( $93.33 \%)$, the diagnosis of AA was confirmed by the examination. Of the patients with AS 5-6, out of 120 patients, $82(68.33 \%)$ underwent the examination, with the diagnosis confirmed in 79(96.34\%) of these patients. Already, for patients with AS 7-10(72 patients), CT was requested for $39(54.16 \%)$, and the diagnosis of acute appendicitis was confirmed in $37(94.87 \%$ ) of these patients.

The sensitivity of AS according to data from the original Alvarado study and when applied in the present study was $30.63 \%$, with specificity of $75 \%$, accuracy of $33.61 \%$ and PPV of $94.44 \%$ (Table 1). Regarding the tomographic findings of $152(63.33 \%)$ patients submitted to such examination, we obtained the following results, according to Table 3 .

The relationship between positive AS and tomographic findings was evaluated, being considered positive in the presence of two or more findings. Of 40 patients who had CT and had positive AS, $26(65 \%)$ had significant tomographic changes. We obtained a positive association between positive AS and the presence of tomographic findings, with Odds Ratio(OR) of 1.665 and $\mathrm{P}=0.1805$ (Table 4). 
Table 3 Tomographic findings obtained in the patients submitted to the examination

\begin{tabular}{lll}
\hline Tomographic & Cases number & $\%$ \\
\hline Findings & 126 & $82,89 \%$ \\
$\begin{array}{l}\text { Thickness of } \\
\text { Appendix }\end{array}$ & \\
Blurring of the & 92 & $60,93 \%$ \\
Adjacent Fat & & \\
Free liquid & 50 & $32,89 \%$ \\
Thickness of wall & 39 & $21,19 \%$ \\
Appendecolite & 23 & $15,13 \%$ \\
Extra luminal gas & 6 & $3,97 \%$ \\
Thickness of cecum & 4 & $2,65 \%$ \\
Inflammatory mass & 3 & $1,99 \%$ \\
\hline
\end{tabular}

Table 4 Relationship between Alvarado score and tomographic findings

\begin{tabular}{llll}
\hline Tomographic & & & \\
\hline Alteration & & & \\
& Yes & No & Total \\
Positive AS & $26(65 \%)$ & $14(35 \%)$ & 40 \\
Negative AS & $58(52,73 \%)$ & $52(47,27 \%)$ & 110 \\
Total & 84 & 66 & 150
\end{tabular}

The relationship between positive AS and gender was also studied. Of the 72 patients with positive AS, $46(63.89 \%)$ were males and $26(36.11 \%)$ were females $(\mathrm{OR}=1.11$ and $\mathrm{P}=0.7210)$. In the present study, the association between the intraoperative findings(phases of AA) and positive AS was evaluated, where $8(11.11 \%)$ patients were in the edematous phase $(\mathrm{OR}=0.8182 ; \mathrm{P}=0,(\mathrm{OR}=0.8128, \mathrm{P}=0.4628)$, $15(20.83 \%)$ in gangrenous phase $(\mathrm{OR}=0.9175, \mathrm{P}=0.8028), 31(43.05 \%)$ phlegmonous phase and $18(25 \%)$ in the perforated phase $(\mathrm{OR}=1.7949$; $\mathrm{P}=0.1278)$ (Table 5).

Table 5 Relationship between Alvarado's score and the appendicitis phase obtained in the anatomopathological study

\begin{tabular}{lllll}
\hline $\begin{array}{l}\text { Appendicitis } \\
\text { phase }\end{array}$ & $\begin{array}{l}\text { Positive } \\
\text { AS }\end{array}$ & $\begin{array}{l}\text { Negative } \\
\text { AS }\end{array}$ & OR & P \\
\hline Normal & 0 & I & $X$ & $X$ \\
Edematous & 8 & 22 & 0,8182 & 0,6474 \\
Phlegmonous & 31 & 80 & 0,8128 & 0,4655 \\
Gangrenous & 15 & 37 & 0,9175 & 0,8028 \\
Perforated & 18 & 26 & 17,949 & 0,1278 \\
\hline
\end{tabular}

OR, odds ratio and statistical significance for $\mathrm{p} \leq 0.05$

When the association was made between age and positive AS, the present study showed that the mean age of patients with negative AS was 28.53years, while the mean number of patients with positive AS was 29.07 years. $\mathrm{P}=0.7587$. Of the patients with negative $\mathrm{AS}(0-4)$, out of a total of $46,44(95.65 \%)$ had histologically proven appendicitis.

\section{Discussion}

AA is one of the most common causes of abdominal pain, accounting for about one-third of patients presenting to emergency services with acute abdomen. Surgeons perform about 280,000 appendectomies per year in the United States. ${ }^{2,10}$ The risk of developing AA during life is around $8.6 \%$ for men and $6.7 \%$ for women. ${ }^{1,3}$ It is the main a disease of adolescents and young adults, with a peak incidence during the $2^{\text {nd }}$ and $3^{\text {rd }}$ decades of life, being uncommon before fiveyears and after 50 years. ${ }^{5,11}$ Regarding gender and age group, studies presented a mean age ranging from $27.82 \pm 9.26$ to $36 \pm 17.78$ years, with a predominance of males $(55.3$ to $70.3 \%)$ and female patients varying between 29.7 and $44.7 \%$ of the samples evaluated. ${ }^{4,12,13}$ In the present study, we present $150(62.5 \%)$ male patients and $90(37.5 \%)$ female patients, mean age of 28.67years. Thus, the age range of AA is in agreement with the literature, being the male predominant. In our series, abdomen US and CT showed sensitivity of $39.13 \%$ and $96.52 \%$, respectively, and specificity was $40 \%$ and $25 \%$. The PPV was $92.3 \%$ for the US and $95.86 \%$ for the CT. The US accuracy of $39.17 \%$ and $92.76 \%$ for CT. According to US-related studies, US sensitivity varied from 68 to $96 \%$ and specificity from 46.7 to $95.9 \%$, with PPV between 82.2 and $94 \%$ and accuracy from 65.7 to $87 \% .^{13}$

With respect to tomography studies, sensitivity varied from 91.2 to $98.5 \%$, specificity from 62.5 to $98 \%$, PPV 92.1 to $98 \%$ and accuracy of $90 \%,{ }^{4,7,9,12}$ In a study carried out by Çaglayan et al. ${ }^{12}$ for cases with suspected AA with AS between 4-6, a total of 297 patients underwent appendectomy and of these, 174 were submitted to the US, with a negative result in 71. Among the latter, 52 had AS between 4-6, being submitted to appendectomy after confirmation of the condition after CT. The mean AS score was 4.9. ${ }^{12}$

In the present study the sensitivity, specificity and accuracy of the US were found to be well below the values described in the literature. Most of the investigations followed to the CT scan. This is mainly due to the fact that US is a dependent examiner, being performed by different radiologists, with diverse experiences and in an emergency setting. In addition, the performance of the US varies according to the characteristics of each patient, such as intra-abdominal fat, excessive gas formation or even failure to visualize the cecal appendix in its retrocecal presentation. In general, the US should be used as the initial examination according to the clinical suspicion, however, in case of doubt, it is essential to complement with advanced radiological examination, avoiding high morbidity and mortality rates. CT showed sensitivity and PPV of $96.52 \%$ and $95.86 \%$, respectively, according to the literary data collected. The specificity was $25 \%$, much lower than that reported in the literature. The test had a good accuracy, in the amount of $92.76 \%$. Such a diagnostic method has been widely used in the suspicion of AA and its differential diagnoses, being important to evaluate the characteristics of the cecal appendix and possible complications. Thus, the rate of negative appendectomies is evident. Thus, CT should remain the main choice in the diagnosis of this sickness. However, waiting to perform the test can lead to a delay in diagnosis, delaying surgery and increasing the chances of complications. The higher costs of CT when compared to US can be offset by a shorter hospital stay and, as mentioned, lower rates of negative appendectomies. Unnecessary study exposes the patient to radiation, and efforts should be made to reduce such risk. In the present study, 39 patients had the diagnosis of appendicitis directly through the US, and despite this diagnosis, CT was still requested for $7(17.95 \%)$ of these patients. Consequently, increasing costs for the hospital is inevitable. 
In this case was observed that appendicitis in the edematous phase was present in 11 patients(4.76\%), 157 in the phlegmonous phase $(67.97 \%), 45(19.48 \%)$ in the gangrenous phase and 2 in the necrosed phase $(0.87 \%)$. The number of negative appendectomies was 16 patients $(6.93 \%)$. In surgical practice, a negative appendectomy rate of $20 \%$ has already been well tolerated..$^{9,10,14}$ According to the recent literature, the rate varies from 5 to $16 \%$, with acceptable upper negative appendectomy rates are accepted in order to minimize the incidence of perforation. ${ }^{13}$ However, such rates are no longer acceptable because although the number of complications in negative appendectomy is low, conditions such as incisional hernia, intestinal obstruction secondary, among others, can result in significant morbidity after the surgical procedure. ${ }^{3}$

In a study conducted by Flum et al., rates of negative appendectomies were reported between $15 \%$ and $34 \%$, with around $15 \%$ being accepted in order to reduce the incidence of perforation. ${ }^{15}$ According to the work conducted by Sousa-Rodrigues et al., ${ }^{16}$ the rates of negative appendectomies found were $17 \% .{ }^{16} \mathrm{~A}$ study concluded by Parks et al. ${ }^{17}$ The US presented a $5 \%$ negative appendectomy rate, a CT scan of $4.3 \%$, and a clinical diagnosis related to the physical examination of $12,2 \%$. For Pickhardt et al. ${ }^{18} 7.5 \%$ was the rate of negative ${ }^{19}$ appendectomy found, for Douglas et al. ${ }^{20}$ It was $15-30 \%$, of $6.8 \%$ in the study by Jo et al. ${ }^{21}$ and $17.8 \%$ for Ozkan, et al. ${ }^{4}$ In a study by Yüksel et al. ${ }^{19}$ the rate of negative appendectomy was $19.4 \%$. For AS $\leq 4$, a rate of $43.5 \%$ was obtained, for AS $5-7$ of $24.1 \%$ and $11 \%$ for AS between $8-10 .{ }^{19}$ According to the prospective study by Antevil et al., ${ }^{22}$ there was a reduction of the rates of negative appendectomies from $16 \%$ to $4 \%$ after the implementation of an early surgical evaluation and $\mathrm{CT}$ for all patients with suspected AA. ${ }^{22}$ Overall, the present study had negative appendectomy rates of $6.93 \%$ for 16 patients. This is in accordance with the cited literature, and is even below the statistics cited by several authors. The low number suggests being due to the high number of CT in the studied patients.

Taking into account the classification made by Alvarado, the following data were obtained: AS 0-4; 46(19.33\%), AS 5-6; $120(50.42 \%)$ and AS $7-10 ; 72(30.25 \%)$, and it was possible to calculate the AS in 238 patients. The sensitivity of the AS according to the data of the original study and when applied in the present study was $30.63 \%$, with specificity of $75 \%$, accuracy of $33.61 \%$ and PPV of $94.44 \%$. The exclusive clinical diagnosis, without imaging studies, of AA was performed in 42 patients (17.4\%).

As cited by Alvarado et al., the score of 7 is given as high probability of AA. Nanjundaiah et al. ${ }^{13}$ obtained sensitivity and specificity of AS, from the cut-off point of 7 , of $58.9 \%$ and $85.7 \%$, respectively. The PPV and the negative predictive value(NPV) of AS were $97.3 \%$ and $19.1 \%$, respectively. ${ }^{6,13}$ Ohle et al. ${ }^{23}$ showed that for a cut-off point of 5 , there was a sensitivity of $99 \%$ and specificity of $43 \%$. For the cut of 7 the sensitivity was of $82 \%$ and specificity of $81 \%$. Based on these results the authors state that an $\mathrm{AS} \leq 5$ as a cutoff point is a good way to exclude AA, while a cut of 7 is not specific enough to indicate surgery. ${ }^{23}$ A retrospective 2007 study found that $5 \%$ of patients with $\mathrm{AS} \leq 3$ were diagnosed with AA and $36 \%$ of patients with AS between 4 and 6 were diagnosed. ${ }^{24}$ Gwynn et al., of the patients who presented with acute abdominal pain in the emergency department, it was found that $8.4 \%$ (12 of 143) of individuals with AA had an AS of less than $5 . .^{25}$

According to Ozkan et al. ${ }^{4}$ in 36 cases(48.6\%), AS was $\geq 7$, between 5 and 6 in 27 cases(36.5\%), and $\leq 4$ in 11 cases(14.9\%), . The sensitivity of AS obtained in the analyzed studies was $54 \%$ to $87.41 \%$, specificity from $73.3 \%$ to $87.9 \%$, PPV from $83.7 \%$ to $96 \%$, and NPV from $29 \%$ to $71 \%, 4 \%$ with an accuracy rate of $57.7 \%$ to $86.5 \%{ }^{4,5,26,27}$ AA was determined in $86 \%$ of patients with $\mathrm{AS} \geq 7$ submitted to $\mathrm{CT}^{4}{ }^{4}$ In the study by Khan et al..$^{28}$ when patients with $\mathrm{AS} \leq 4$ were divided into two groups, one being those with discharge after monitoring and the other those who were submitted to surgery, 17 of 100 patients were in the first group and were dispensed. Three of the patients returned within 48hours and the AS was calculated as 7, being submitted to surgery and AA was detected(17\%). ${ }^{28}$

In a study conducted by Yuksel et al. ${ }^{19} 37$ patients with $\mathrm{AS} \leq 4$ were dispensed, two were readmitted and one detected AA(5.4\%). The same author mentions that 23 patients with $\mathrm{AS} \leq 4$ underwent surgery and AA was present in $13(56.5 \%)$ patients. ${ }^{19}$ According to Yildirim et al. ${ }^{9} 14$ patients with AS $\leq 4$ underwent surgery and in $13(92.8 \%)$ were detected AA. Of the $72(30.25 \%)$ patients with AS 7-10 the CT was requested for $39(54.16 \%)$ and the diagnosis of AA was confirmed in $37(94.87 \%)$ of these patients. ${ }^{9}$ In the present study, CT Was a useful test for the diagnosis of AA, taking into account the low sensitivity found for AS. In view of the need for accurate diagnosis, just with clinical diagnosis were 42 patients $(17.4 \%)$.

According to the data of the present study, the sensitivity of the AS was low, of $30.63 \%$ when compared with the literature studied. The PPV(94.44\%) and the specificity $(75 \%)$ are in agreement with the literary data. The accuracy was $33.61 \%$. When the cutoff point of 8 was used, the sensitivity of the EA fell to $13.45 \%$ and the VPP increased to $96.87 \%$.

The analysis performed by Ohle et al., ${ }^{23}$ corroborates with the analyzed data, where with the increase of the AS cutoff there is a decrease in sensitivity. It was quoted by such author that the cutoff point of 5 or less is ideal to exclude appendicitis and a value of 7 is not specific enough to subject the patient to the surgical procedure. The AS is an index of easy access in the suspicion of AA, however it does not contain certain parameters, such as age, sex and duration of the symptoms before the presentation. It has great value in hospitals with few resources, because the decision to operate or not, is based on clinical judgment, being the main diagnostic tool. However, as evidenced in the present study, an AS 0-4 is not sufficient to exclude appendicitis, since $46(19.33 \%)$ patients fall within this range, and of that total $30(65.21 \%$ ) were submitted To CT, and in $28(93.33 \%$ ) the diagnosis was reached through such imaging. Of these 46 patients, $44(95.65 \%)$ had AA, proven at the anatomopathological examination. These data are above those reported in the literature, and McKay et al. showed that $5 \%$ of patients with AS $\leq 3$ were diagnosed with

AA and $36 \%$ of patients with AS 4-6 were diagnosed. In the same way as Gwynn et al., ${ }^{25}$ evidenced that $8.4 \%$ of patients with AS $0-4$ were diagnosed. The data of Yildirim et al. ${ }^{9}$ are in agreement with the present study, where the author cites that of 14 patients with AS $\leq 4$, in $13(92.8 \%)$ AA was proven. Thus, patients with $\mathrm{AS} \leq 4$, where in the original Alvarado article would exclude appendicitis, should be monitored. For those discharged, they should be informed of the need for early reevaluation in the persistence of clinical manifestations. Patients with AS 5-6 should be hospitalized for monitoring and complementation with imaging methods, preferably CT. In the present study, the majority of patients $(50.42 \%)$ fit into this group, further evidencing the need for imaging tests. Those with AS $\geq 7$ may undergo the surgical procedure without image complementation. 
The relationship between positive AS and tomographic findings was evaluated, being considered positive in the presence of two or more findings. Of 40 patients who had $\mathrm{CT}$ and with positive AS, $26(65 \%)$ had significant tomographic changes. We found a positive association between positive AS and the presence of tomographic findings, with $\mathrm{OR}=1.665$ and $\mathrm{P}=0.1805$. The association between the intraoperative findings (phases of AA) and positive AS was also evaluated, where $8(11.11 \%)$ patients were in the edematous phase $(\mathrm{OR}=0.8182 ; \mathrm{P}=0.6474) ;(\mathrm{OR}=0.8128, \mathrm{P}=0.4665), 15(20.83 \%)$ in the gangrenous phase $(\mathrm{OR}=0.9175, \mathrm{P}=0.8028)$ and $18(25 \%)$ in the perforated phase $(\mathrm{OR}=1.7949, \mathrm{P}=0.1278)$. It was evidenced an association between AS and gender, where male patients are $11 \%$ more likely to be positive. There was an increase in the correlation of AS in patients with advanced age.

\section{Conclusion}

The present study demonstrated that there is a positive association between AS positive and the presence of tomographic findings, with AS being higher in the presence of 2 or more CT findings, as well as the association between positive AS and perforation phase. With the implementation of tomography for the suspicion of AA, there was a considerable reduction in the rate of negative appendectomy, which is, therefore, the better diagnostic tool when compared to the Alvarado score.

\section{Acknowledgements}

None.

\section{Conflict of interest}

Author declares that there is no conflict of interest.

\section{References}

1. Birnbaum BA, Wilson SR. Appendicitis at the millenium. Radiology. 2000;215(2):337-348

2. Livingston EH, Woodward WA, Sarosi GA, et al. Disconnect between incidence of nonperforated and perforated appendicitis: Implications for pathophysiology and Management. Ann Surg. 2007;245(6):886-892.

3. Tan WJ, Acharyya S, Goh YC, et al. Prospective Comparison of the Alvarado Score and CT Scan in the Evaluation of Suspected Appendicitis: A Proposed Algorithm to Guide CT Use. J Am Coll Surg. 2015;220(2):218-224

4. Ozkan S, Duman A, Durukan P, et al. The accuracy rate of Alvarado score, ultrasonography, and computerized tomography scan in the diagnosis of acute appendicitis in our center. Niger J Clin Pract. 2014;17(4):413-418.

5. Freitas RG, Pitombo MB, Maya MCA, et al. Apendicite aguda. Rev Hosp, UERJ, Rio de Janeiro, Brazil; 2009;8:38-51.

6. Alvarado A. A practical score for the early diagnosis of acute appendicitis. Ann Emerg Med. 1986;15(5):557-564.

7. Shogilev DJ, Duus N, Odom SR, et al. Diagnosing Appendicitis: Evidence-Based Review of the Diagnostic Approach in 2014. WJ Emerg Med. 2014;15(7):859-871.

8. Montandon Júnior ME, Montandon C, Fiori GR, et al. Apendicite aguda: achados na tomografia computadorizada - ensaio iconográfico. Radiol Bras. 2007;40(3):193-199.

9. Yıldırım E, Karagülle E, Kirbaș I, et al. Alvarado scores and pain onset in relation to multislice CT findings in acute appendicitis. Diagn Interv Radiol. 2008;14(1):14-18.
10. Duda JB, Lynch ML, Bhatt S, et al. Computed Tomography Mimics of Acute Appendicitis: Predictors of Appendiceal Disease Confirmed at Pathology. J Clin Imaging Sci. 2012;2:73

11. Limpawattanasiri C. Alvarado score for the acute appendicitis in a provincial hospital. J Med Assoc Thai. 2011;94(4):441-449.

12. Çağlayan K, Günerhan Y, Koç A, et al. The role of computerized tomography in the diagnosis of acute appendicitis in patients with negative ultrasonography findings and a low Alvarado score. Ulus Travma Acil Cerrahi Derg. 2010;16(5):445-448.

13. Nanjundaiah N, Ashfaque M, Venkatesh S, et al. A comparative study of RIPASA score and ALVARADO score in the diagnosis of Acute Appendicitis. J Clin Diagn Res. 2014;8(11):3-5.

14. Lane MJ, Liu DM, Huynh MD, et al. Suspected Acute Appendicitis: Nonenhanced Helical CT in 300 Consecutive Patients. Radiology. 1999;213(2):341-346.

15. Flum DR, Morris A, Koepsell T, et al. Has misdiagnosis of appendicitis decreased over time? A population-bases analysis. JAMA. 2001;286(14):1748-1753.

16. Sousa-Rodrigues $\mathrm{CF}$, Rocha AC, Rodrigues AKB, et al. Correlação entre a Escala de Alvarado e o aspecto macroscópico do apêndice em pacientes com apendicite. Rev Col Bras Cir. 2014;41(5):336-340.

17. Parks JS, Jeong JH, Lee JI, et al. Accuracies of diagnostic methods for acute appendicitis. Am Surg. 2013;79:101-106.

18. Pickhardt PJ, Lawrence EM, Pooler BD, et al. Diagnostic performance of multidetector computed tomography for suspected acute appendicitis. Ann Intern Med. 2011;154(12):789-796.

19. Yüksel Y, Dinç B, Yüksel D, et al. How reliable is the Alvarado score in acute appendicitis? Ulus Travma Acil Cerr Derg. 2014;20(1):12-18.

20. Douglas CD, Macpherson NE, Davidson PM, et al. Randomised controlled trial of ultrasonography in diagnosis of acute appendicitis, incorporating the Alvarado score. BMJ. 2000;321(7266):919-922.

21. Jo YH, Kim K, Rhee JE. The accuracy of emergency medicine and surgical residents in the diagnosis of acute appendicitis. Am J Emerg Med. 2010;28(7):766-770.

22. Antevil JL, Rivera L, Langenberg BJ, et al. Computed tomography-based clinical diagnostic pathway for acute appendicitis: prospective validation. Journal of the American College of Surgeons. 2006;203(6):849-856.

23. Ohle R, O'Reilly F, O'Brien KK, et al. The Alvarado score for predicting acute appendicitis: a systematic review. BMC medicine. 2011;9:139-152.

24. McKay R, Shepherd J. The use of the clinical scoring system by Alvarado in the decision to perform computed tomography for acute appendicitis in the ED. Am J Emerg Med. 2007;25(5):489-493.

25. Gwynn LK. The diagnosis of acute appendicitis: clinical assessment versus computed tomography evaluation. J Emerg Med. 2001;21(2):119-123.

26. Jalil A, Shah SA, Saaiq M, et al. Alvarado scoring system in prediction of acute appendicitis. J Coll Physicians Surg Pak. 2011;21(12):753-755.

27. Chong CF, Thien A, Mackie AJ, et al. Comparison of RIPASA and Alvarado scores for the diagnosis acute appendicitis. Singapore Med J. 2011;52(5):340-345.

28. Khan I, Rehman A. Application of Alvarado scoring in diagnosis of acute appendicitis. J Ayub Med Coll Abbottabad. 2005;17(3):41-44. 